\title{
Por um planeamento urbano mais sustentável
}

A preparação e elaboração deste Dossier temático da CIDADES, Comunidades e Territórios resultou da vontade de duas arquitetas, investigadoras integradas do DINÂMIA'CET-Iscte, em oferecer à comunidade científica um momento de reflexão e de debate, nacional e internacional, sobre a cidade e o território e o seu potencial para repensar o planeamento urbano face à exigência da sustentabilidade.

Uma reflexão que espelha problemáticas que extravasam a esfera científica, que abrangem o desígnio da sociedade civil e que repercutem também o imaginário das gerações mais novas. Enquanto mães de pequenas crianças e professoras de jovens adultos, estudantes de arquitetura, frequentemente testemunhamos: i) para o primeiro caso, como as suas histórias imaginárias sugerem, desde as mais variadas perspetivas, vontades de vislumbrar um mundo melhor, mais bonito e justo; e ii) no segundo caso, a criatividade do desenho e das ideias ao serviço da transformação da cidade e/ou do território procurando proporcionar soluções de melhores habitats.

No início de 2020 o mundo testemunhou a rápida propagação de um novo vírus, usualmente designado COVID19, tendo sido forçado a impor restrições de sociabilidade e de mobilidade, à escala global e de uma forma inesperada. As cidades e os territórios tiveram que rapidamente se readaptar às novas restrições, com elevados custos económicos e humanos, mas evidentes benefícios ambientais através da redução de emissões de carbono. Em Portugal, a crise pandémica levou o Presidente da República a decretar, a 18 de março de 2020, o estado de emergência, com fundamento na verificação de uma situação de calamidade pública e abrangendo todo o território nacional.

Com a call aberta aproximadamente durante um mês e meio (14/04/2020 a 01/06/2020), incluindo o período de confinamento, foram rececionadas ao presente Dossier temático 27 submissões de artigos científicos e 5 entrevistas. Um número elevado de submissões, recebido com bastante agrado, tendo motivado às mesmas editoras deste número temático, a organização de um número especial para a revista CIDADES, Comunidades e Territórios, cuja data de publicação está planeada para a Primavera de 2021. Esse número especial irá dar continuidade ao presente Dossier temático, alargando, deste modo, a possibilidade de divulgação do material submetido e aceite para publicação.

No presente Dossier temático incluem-se ao todo dez textos, 3 entrevistas e 7 artigos científicos, submetidos ao escrutínio e avaliação científica por 2 ou mais revisores nacionais/internacionais, cujo trabalho, tempo e dedicação estamos naturalmente reconhecidas e gratas.

Uma entrevista ao arquiteto Francisco Silva Dias abre o presente Dossier temático. Realizada por João Cunha Borges e Teresa Marat-Mendes a 13 de maio de 2019, a este arquiteto foi solicitado um olhar retrospetivo sobre o período de 1960 a 1972, momento em que este esteve dedicado à coordenação do Plano de Urbanização de Chelas (a partir de 1962) e, em particular, à pormenorização das suas primeiras três 'Zonas' (I, J e N2). A entrevista sublinha a ideia de que as propostas urbanas apresentadas para a criação de um novo bairro habitacional situado na zona oriental da cidade de lisboa - desenvolvidas por uma equipa de técnicos municipais - não esqueceram o que de mais atual se colocava em prática além-fronteiras. Ao contrário da, já desatualizada, fusão da cidade com o campo, em Chelas a cidade foi sendo erguida aos poucos, aparecendo-nos de forma "compacta", com as zonas verdes em redor. A implementação do Plano de Urbanização de Chelas deixou para segundo plano o tratamento do espaço público e a prometida mobilidade social. Hoje, face às atuais exigências da sustentabilidade, revela-se imperioso cuidar do (pré)ambicionado equilíbrio social. 
Segue-se a entrevista que, em fevereiro de 2019, Joana Carolina Schossler fez a Bernard Toulier, arqueólogo e historiador de arte francês, especialista em cultura balneária. Neste encontro, no âmbito da abordagem à tomada de consciência da problemática do aumento do nível do mar e no que se poderá esperar do "futuro das cidades balneárias", foi discutida a possibilidade de a população abandonar a cidade balnear para se deslocar para o interior do país. Trata-se de, como refere o entrevistado, dar resposta à necessária pesquisa sobre a "sobrevivência à beiramar". O tratamento nefasto que foi dado ao longo dos anos ao território costeiro, levou a que, em dezembro de 2017, as Nações Unidas tenham declarado a necessidade de implementar uma iniciativa internacional que vise defender a Década Internacional da Oceanografia para o Desenvolvimento Sustentável, período que será observado a partir de 2021 e até 2030. Urge, pois, pensar sobre o futuro uso dos oceanos, das praias e dos recursos naturais para um futuro planeamento urbano mais sustentável.

É através de uma conversa entre as arquitetas Mariana Salvador e Carolyn Steel, esta última autora dos livros Hungry City: How Food Shapes our Lives de 2008 e do recentemente publicado Sitopia: how food can save the world, que se organiza a terceira entrevista incluída neste Dossier. Com um enfoque numa perspetiva evolutiva acerca da relação entre a alimentação, o homem e a cidade, ao longo da história, proporciona-se nesta entrevista um proveitoso debate sobre o potencial do papel da alimentação na promoção de novos desafios sociais, urbanos e ambientais capazes de transformar as cidades e os territórios em habitats mais sustentáveis.

O primeiro artigo científico que abre o presente Dossier, elaborado por Ricardo Cunha Dias, Diogo Guedes Vidal, Paulo Castro Seixas e Rui Leandro Maia, tem por título "Os espaços verdes e as preocupações com a sustentabilidade nos Planos Diretores Municipais de $3^{a}$ geração: Análise comparativa das Áreas Metropolitanas em Portugal". Os autores analisam o principal instrumento de planeamento territorial à escala municipal, o Plano Diretor Municipal (PDM), através do papel que estes atribuem aos espaços verdes, assumindo o seu intrínseco contributo para a sustentabilidade das cidades. Sob esta perspetiva, são analisados os PDMs das duas principais áreas metropolitanas Portuguesas, Lisboa e Porto. Conclui-se acerca da existência de um contínuo negligenciar de aspetos socio-ecológicos dos espaços verdes por parte dos PDMs; propondo os autores uma necessária reformulação destes instrumentos de planeamento quer formal quer sistémica, rumo à sustentabilidade.

O artigo "Bases para o planejamento territorial urbano: Uso de imagens hiperespectrais para a identificação de áreas geradoras de funções ecológicas de suporte”, da autoria de quatro investigadores da Universidade de Brasília, Rubens Amaral, Maria do Carmo de Lima Bezerra, Gustavo Macedo de Mello Baptista, Rômulo José da Costa Ribeiro e Aline da Nóbrega Oliveira, oferece-nos a identificação do potencial dos processos de captura de carbono numa área do território do Distrito Federal do Brasil, designadamente a partir do uso de ferramentas de sensoriamento remoto que procuram identificar os depósitos naturais (floresta, savana, água) que absorvem e capturam o dióxido de carbono $\left(\mathrm{CO}_{2}\right)$ da atmosfera, de modo a quantificar e qualificar os seus ecossistemas. A investigação realizada permite confirmar que as variações na concentração de $\mathrm{CO}_{2}$ são resultantes da presença de maior ou menor concentração de vegetação no território, mas também do tipo de vegetação existente. Assim, os autores concluíram que as ferramentas de sensoriamento remoto adotadas são idóneas e permitem trazer novas perspetivas para as futuras decisões no planeamento urbano.

Segue-se o artigo "Refinando uma história de luta pela cidade: A Cooperativa Habitacional Marianinha de Queiroz, Caxias do Sul/RS (Brasil)", da autoria de Jasmine Pereira Vieira e Susana de Araújo Gastal da Universidade de Caxias do Sul, no Brasil. Trata-se de uma análise in loco da comunidade que habita as moradias daquela cooperativa, localizadas na periferia do município de Caxias do Sul, no estado do Rio Grande do Sul. A participação da população neste estudo, através da recolha e escuta ativa dos seus testemunhos, permite concluir que a periferização da comunidade face ao centro urbano é um dos fatores que conduz à sua segregação, nomeadamente pela dificuldade no acesso à educação, saúde e transportes. Assim se verifica que as opções organizativas da cidade e, em particular, da sua periferia, tem consequências diretas no exercício da cidadania.

O quarto artigo incluído neste Dossier é da autoria de Teresa Marat-Mendes, João Cunha Borges, Sara Silva Lopes e Mafalda Matos Pereira. Este trabalho apresenta contributos do Projeto SPLACH - Spatial Planning for Change, no que concerne à potencial integração do sistema alimentar com o planeamento urbano rumo a uma Sustentabilidade Urbana. O seu título sugestivo "Where the field have no name: Urban-rural transitions in the 
Lisbon region planning history", é um tributo à Banda de música irlandesa U2, que através da canção "Where the streets have no name" produziu um vivo relato sobre a articulação entre as dimensões espaciais e sociais de um determinado espaço urbano, em Belfast. Centrados na Região de Lisboa, os autores preconizam através do seu artigo uma análise crítica sobre a evolução deste território e dos seus usos de solo, ao longo dos tempos, criticando a forma como o território e as suas intrínsecas capacidades produtivas (sociais, ambientais e culturais) têm sido negligenciadas até à data pelo planeamento, inibindo o seu reconhecimento funcional e identitário, necessários para a promoção de um desenvolvimento que se quer sustentável. $\mathrm{O}$ artigo aborda a existente dicotomia urbanorural patente no atual planeamento urbano português, com profundos impactos no funcionamento do sistema alimentar e na sua sustentabilidade urbana. Por último, os autores identificam um conjunto de propostas para um melhor aproveitamento dos solos produtivos da Região de Lisboa, considerando os desafios colocados pelas agendas internacionais e nacionais.

No artigo "Processos de transformação urbana: uma tipificação baseada na urbanidade, na centralidade e na evolução da população dos territórios", os autores Jan Wolf, Paulo Batista e João Lourenço Marques, da Universidade de Aveiro e membros do Projeto SPLACH - Spatial Planning for Change, clarificam como a utilização de três conceitos operativos - urbanidade, centralidade e evolução da população - atuam na análise e medição das freguesias de Portugal Continental (como unidades territoriais de base) e contribuem para identificar e caracterizar novas respostas analíticas no estudo dos processos de transformação urbana. Os autores identificam os processos de transformação urbana, os seus padrões geográficos e procuram percebê-los de forma relacional, tendo em conta as estruturas territoriais que lhes subjazem. Do ponto de vista empírico, esta é uma abordagem que permite sínteses entre diferentes escalas, destacando-se, por exemplo, a polarização em torno dos maiores aglomerados urbanos do país, mas também a consolidação urbana que ocorre nos polos urbanos de pequena dimensão nas regiões rurais em acentuado declínio.

Segue-se o artigo de Ana Mélice Dias e Teresa Marat-Mendes, "The morphological impact of municipal planning instruments on urban agriculture: The case of Lisbon's Greater Area", dando continuidade a uma abordagem crítica acerca da desejável necessidade de revisão dos instrumentos de planeamento à escala municipal os PDMs, para uma desejável transição sustentável. As autoras destacam a necessidade de um maior conhecimento sobre os impactes dos aspetos morfológicos da agricultura urbana, enquanto fase de produção do sistema alimentar no espaço urbano. Focando-se na Grande área de Lisboa, o artigo identifica quais as estratégias de planeamento previstas pelos PDMs em relação à agricultura urbana e, consequentemente, qual o seu impacte nas soluções agrícolas urbanas existentes. Concluem as autoras que as decisões morfológicas que norteiam o planeamento urbano contemporâneo, no que concerne à agricultura, restringem-se a opções estéticas e programas que primariam atividades de lazer, deixando em aberto, contudo, a leitura de que oportunidades e soluções de projetos que defendam crescimento económico e diversidade ecológica são ainda escassas mas possíveis.

Encerra-se este Dossier com um artigo também produzido no âmbito do Projeto SPLACH, "O sistema alimentar em Portugal: transições para a sustentabilidade e políticas públicas”, pelas autoras Maria de Fátima Ferreiro, Isabel Salavisa e Sofia Bizarro. Focando no importante papel do sistema alimentar para uma transição sustentável do planeamento urbano português, este artigo promove uma análise critica das políticas públicas com um papel central nessa desejável transição, através da referência ao caso português. As autoras sublinham a complexidade do sistema alimentar, através da diversidade de atores que este integra, bem como das variadas escalas territoriais em que se incorpora, propondo uma reflexão atenta sobre a dimensão da governança, que se inscreve no domínio de investigação da política pública, por forma a oferecer uma maior coerência e integração aos vários elementos que governam este sistema em particular. Em conclusão, sugerem as autoras a necessidade de novas abordagens territoriais e de governança para o planeamento do sistema alimentar, por forma a contribuir para um incremento da autossuficiência e do reforço da resiliência das comunidades, fatores identificados como essenciais para uma transição sustentável e perante o atual contexto de crise.

Teresa Marat-Mendes, Professora Associada com Agregação no Departamento de Arquitectura e Urbanismo do Iscte e Investigadora integrada no DINÂMIA'CET-Iscte.

Patrícia Bento d'Almeida, Investigadora integrada no DINÂMIA'CET-Iscte. 
Editoras do Dossier

\section{Financiamento}

O presente dossier temático surge no âmbito do projeto de investigação "SPLACH - Spatial Planning for Change" (POCI-01-0145-FEDER-016431), no DINÂMIA'CET-Iscte coordenado por Teresa Marat-Mendes, financiado por Fundos Europeus Estruturais e de Investimento (FEEI) através do Programa Operacional Competitividade e Internacionalização (COMPETE 2020) na sua componente FEDER, e por Fundos Nacionais através da Fundação para a Ciência e a Tecnologia na sua componente OE.

Parte da investigação conduzida para a elaboração do presente dossier temático é também oriunda do projeto de pós-doutoramento "O LNEC e a História da Investigação em Arquitectura" (SFRH/BPD/117167/2016), desenvolvido por Patrícia Bento d'Almeida, e financiado pela Fundação para a Ciência e a Tecnologia através do programa de financiamento FSE.

\section{Agradecimentos}

As Editoras do Dossier agradecem à equipa editorial da revista CIDADES, Comunidades e Territórios, particularmente a Maria Assunção Gato, Ana Rita Cruz e Mariana Leite Braga, pelo suporte dado ao longo de todo o processo. As Editoras do Dossier agradecem ainda a todos os revisores, especialistas independentes que, de acordo com o modelo de revisão de pares da revista, avaliaram e escrutinaram cuidadosamente cada um dos artigos submetidos ao presente Dossier, promovendo uma edição de qualidade. 